\title{
Design Fuel Efficiency on a Gas Turbine Generator Using a Fuzzy Logic Controller
}

\author{
Astrie Kusuma Dewi ${ }^{1, *}$ Chalidia Nurin Hamdani ${ }^{1}$ Damita Adhi Pratama ${ }^{1}$ Agus \\ Heriyanto $^{1}$
}

\author{
${ }^{1}$ Polytechnic of Energy and Mineral Akamigas, 58315, Indonesia \\ *Corresponding author.Email: astrie.dewi@esdm.go.id
}

\begin{abstract}
The Gas Turbine Generator (GTG) is an important part of the utility unit at a private company PT. XYZ, namely as a supplier of electricity for the entire plant. The performance of the control system needs to be considered because it is related to efficiency factors, especially to regulate the amount of fuel gas burned. Currently, the Gas Turbine Generator (GTG) installed on the existing Turbine using Proportional Integral Derivative (PID) as the controller. It takes a dynamic process for the reliability of the control system used. In this paper, we propose a Fuzzy Logic Control for fuel gas system. Fuzzy logic control was designed using Mamdani inference with 5 inputs and 1 output. The results of the Fuzzy Logic Controller design using MATLAB simulation obtained a dead time (td) of $2.5 \mathrm{~s}$, a rise time (tr) of $69.87 \mathrm{~s}$, a time constant (tc) of $39.89 \mathrm{~s}$ and a settling time (ts) of $95.36 \mathrm{~s}$.
\end{abstract}

Keywords: Gas Turbine Generator, Fuzzy Logic Control, Fuel Efficiency.

\section{INTRODUCTION}

The utility unit in a plant plays an important role, one of which is as a supplier of electricity supply. The electricity supply in this utility unit is generated from the operation of the gas turbine generator. Gas Turbine Generator is a process that cannot be intervened because it has a very high risk. If something goes wrong, such as a shutdown, the entire operating area will be blackout. A gas turbine generator is a device that uses gas as a fluid to turn a turbine with internal combustion so that it can rotate the generator and generate electricity. Fuel in the turbine serves to drive the turbine. Currently fuel control is set using PID. The resulting control signal is very aggressive, causing waste in fuel consumption.

Fuzzy logic is widely used in machine controls, Isizoh, et al conducted research the temperature control system using fuzzy logic is implemented using a microcontroller, the results obtained are being able to perform a controlled temperature output function [1]. Another study was conducted by Wardhana et al, who carried out fuzzy implementation Robot arm model, using a fuzzy controller to get an average settling time of 0.497 seconds, and an average rise time of 0.277 seconds faster than conventional PID controllers. [2]. Research that has been conducted by Karande et al regarding the design of a gas turbine using a Fuzzy PID controller is focused on designed to stabilize output frequency and output electrical voltages in presence of variable power demand which acts as disturbance in transmission and distribution system.[3]. In this research, fuzzy logic control design will be carried out on the fuel gas turbine generator control system with the aim of reducing fuel losses.

\section{METHOD}

When talking about fuzzy, it will consist of a rule base, membership functions and an inference procedure. Currently, fuzzy has been applied in various fields, including for various control applications in refineries, in academic or in other industries.[4]. For example, for example, fuzzy logic has also been applied in the academic field, fuzzy logic is used to determine the suitability of thesis themes with student interests. [5]. Fuzzy logic application as a control method has been carried out by Elnour, et al. in their research that applies fuzzy logic control to temperature control systems. in that study, they compared their results with PID. Fuzzy logic control has a faster and more stable response than PID control [6]. In other studies that have been conducted by Sneha et al, using fuzzy PID controllers for heating 
control systems, in this study the PID controller design was applied to regulate heating systems. The results obtained from this study are that the heating system can be adjusted as desired and has a better performance than PID in general [4].

\subsection{Fuzzy Logic Control}

Fuzzy Logic Controller is a system that can represent human knowledge in a mathematical form that is more like a human way of thinking. Controllers with Fuzzy Logic Controllers have the advantage of being able to control complex, non-linear, or systems that are difficult to represent in a mathematical form. In addition, information in the form of knowledge and experience has an important role in recognizing system behavior in the real world. The way Fuzzy Logic Controller works in general consists of input, process and output. Fuzzy Logic Controller is a set theory that was developed to overcome the concept of value that lies between truth and error. By using Fuzzy Logic Controller logic the resulting value is not only yes (1) or no (0) te but all possibilities between 0 and 1. How Fuzzy Logic Controller works and the general architecture are shown in Figure 1[4] [3][7].

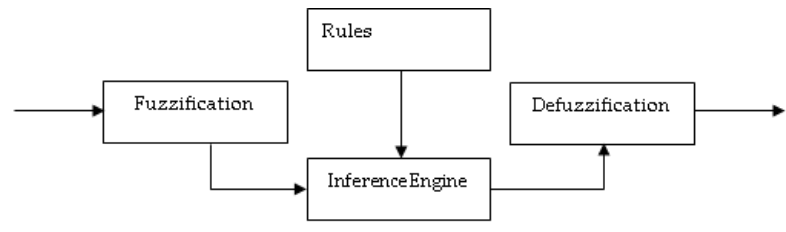

Figure 1 General architecture of fuzzy logic control

\subsubsection{Fuzzification}

Fuzzification is a process to change an input from a crisp form to a Fuzzy Logic Controller (linguistic variable) which is usually presented in the form of a Fuzzy Logic Controller set with a function of its respective membership.

\subsubsection{Basic rules of Fuzzy Logic Controller}

The basic rule or rule base in Fuzzy Logic Controller is a form of relation rule / implication "If-Then" or "IfThen"

\subsubsection{Fuzzy Logic Controller reasoning engine (interference engine)}

The reasoning engine (Inference Engine) is an implication process in reasoning the input value in order to determine the exit value as a form of decision making. In the max-min reasoning, the first process to do is perform the min operation of the fuzzification layer output signal, which is followed by the max operation to find the output value. The method commonly used is the Mamdani method or Sugeno method. In this study the Mamdani method was used

\subsubsection{Defuzzification}

Defuzzification is the process of mapping the set of Fuzzy Logic Controller and crisp capability, this process is the opposite of the fuzzification process.

\subsection{Gas Turbine Generator}

Basic components of gas turbine generator are the air compressor, a combustor and the turbine. The principle of operation of the gas turbine are starts from the air entering through the inlet to be compressed by the multistage axial flow compressor and exiting to the combustion chamber to start cycling. The injected fuel mixes with the compressed air continuously by adjusting the flow rate between the fuel and air. The pressurized working fluid from combustion moves the blade so that the turbine rotates. Then the turbine drives a generator to produce electrical power.[8]

In the fuel gas system, there are five input parameters that become the fuel control system parameters. All these parameters have a significant impact on the process in the field. There is power turbine, air inlet compressor, pressure discharge compressor, combustor temperature, and gas produce. Power Turbine (NPT) is a component that transfers enthalpy of exhaust gas into kinetic energy. Air inlet Compressor (TI) is The temperature of the air inlet that enters the compressor and affects combustion efficiency. Pressure Discharge Compressor (PCD) is a key factor in gas turbine performance. The function of combustion is to heat the compressed air to a certain degree so that the molecules expand rapidly and produce enough energy to drive the turbine wheels, so the combustor temperature is temperature the function of combustion is to heat the compressed air to a certain degree so that the molecules expand rapidly and produce enough energy to drive the turbine wheels, so Combustor Temperature (T5) is temperature resulting from the process. Gas Produce (NGP) is EGF or Gas Meter Fuel Valve is the final element pad fuel gas system which functions as a regulator of the fuel to the combustion chamber. The distribution of conditions is carried out in accordance with the engine performance map.[9]

\section{RESULT AND DISCUSSION}

In this research, five inputs were used based on the factors that affect the performance of the gas turbine. Five inputs and one output, the five inputs are Air Inlet Compressor (TI), Pressure Discharge Compressor (PCD), Gas Produce (NGP), Power Turbine (NPT), Combustor Temperature (T5). And Gas Meter Fuel Valve (EGF) as output. As shown as in Table 1 that each input parameter has a range value that will be used for the fuzzification process. This section determines the membership function of each input and output. 
For example, the membership function in Power Turbine (NPT). The power turbine has a load condition in the value range between $0-5500 \mathrm{~kW}$. Based on the load performance of the power turbine, nine membership functions are made for this situation, starting from load
A to load I, as shown in table 2 below. For example, load A the type is "gaussmf" and the value for the center is " 0 ". And Figure 2 is the result of the implementation of the membership function editor using the Mamdani Method in the MATLAB software.

Table 1. Parameter for Input and Output

\begin{tabular}{lll}
\multicolumn{1}{c}{ Parameter } & & As \\
\hline Air Inlet Compressor (TI) & Input & $-20-120 \mathrm{~F}$ \\
Pressure Discharge Compressor (PCD) & Input & $120-190 \mathrm{psig}$ \\
Gas Produce (NGP) & Input & $0-100 \%$ \\
Power Turbine (NPT) & Input & $0-5500 \mathrm{~kW}$ \\
Combustor Temperature T5) & Input & $500-1300 \mathrm{~F}$ \\
Gas Meter Fuel Valve (EGF) & Output & $0-75 \mathrm{mmBTU} / \mathrm{H}$ \\
\hline
\end{tabular}

Table 2. Membership function for power turbine

\begin{tabular}{llc}
\hline Name & Type & Center \\
\hline Load A & "gaussmf" & 0 \\
Load B & "gaussmf" & 700 \\
Load C & "gaussmf" & 1400 \\
Load D & "gaussmf" & 2100 \\
Load E & "gaussmf" & 2800 \\
Load F & "gaussmf" & 3500 \\
Load G & "gaussmf" & 4200 \\
Load H & "gaussmf" & 4900 \\
Load I & "gaussmf" & 5600 \\
\hline
\end{tabular}

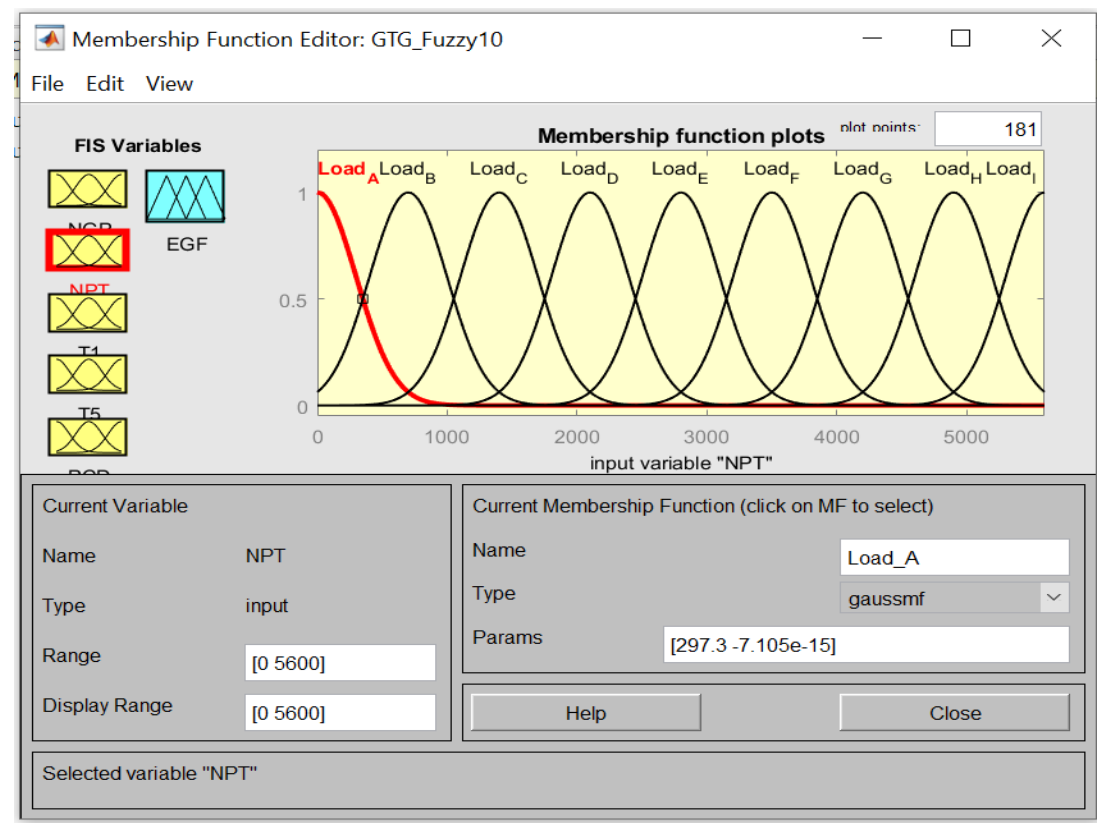

Figure 2 Membership function Editor for Power Turbine (NPT)

The final element in the fuel gas system is called EGF or commonly known as the gas meter fuel valve which functions as a regulator of the fuel to the combustion chamber. the gas meter fuel valve has flow range $0-75$ $\mathrm{mmBTU} / \mathrm{H}$. Determination of the membership function on the gas meter fuel valve (EGF) as output is based on the amount of fuel obtained from engine performance, starting from the gas meter fuel valve EGF "A" to EGF "I" shown in Table 3 below. For example, EGF A, the type is "gaussmf" and the value of the center is " 20 ". In this research, Gas Meter Fuel Valve (EGF) using flow range $20-65 \mathrm{mmBTU} / \mathrm{H}$. And figure 3 is a membership function editor for gas meter fuel valve (EGF). 
In order to evaluate control system designed and compare it to the existing PID control, we simulated it by using MATLAB software. Simulation was made to generate control system response: transient and steady- state response. Then, the control system response was analyzed in term of deadtime, time constant, rise time, and settling time. Figure 4 shown Response Transient For FLC_GTG.

Table 3. Gas Meter Fuel Valve (EGF)

\begin{tabular}{lll} 
Name & Type & Center \\
\hline EGF A & "gaussmf" & 20 \\
EGF B & "gaussmf" & 25.63 \\
EGF C & "gaussmf" & 31.25 \\
EGF D & "gaussmf" & 36.88 \\
EGF E & "gaussmf" & 42.5 \\
EGF F & "gaussmf" & 48.13 \\
EGF G & "gaussmf" & 53.75 \\
EGF H & "gaussmf" & 59.38 \\
EGF I & "gaussmf" \\
\hline
\end{tabular}

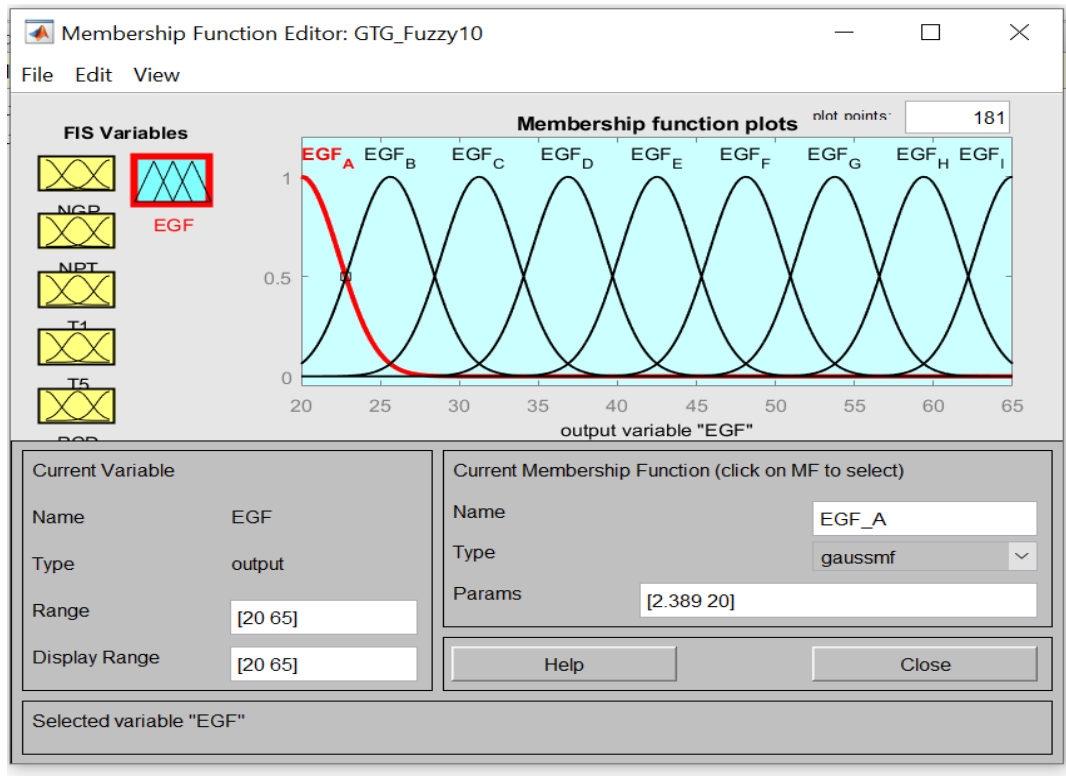

Figure 3 Membership function Editor for EGF

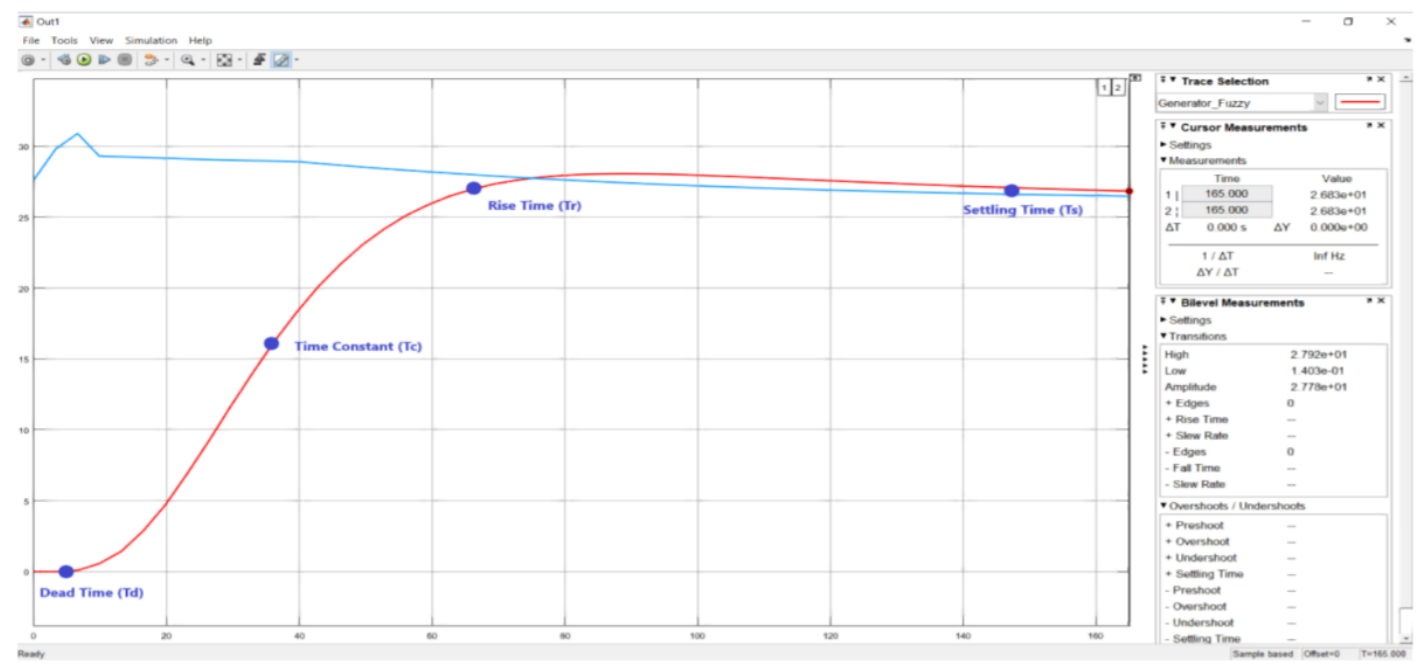

Figure 4 Response Transient For FLC_GTG 
For simulation test, we used set point value about 27.5 MMscfd. Simulation result is shown by Figure 4. As we can see in the figure, fuzzy control logic system generator turbine gas (FLC_GTG) response is more stable than the PID Existing generator turbine gas (PID_E_GTG) system response in term of steady-state. More comprehensive and qualitative analysis is presented in Table 4.

Table 4. Response Transient Result

\begin{tabular}{llllll}
\hline Response & $\begin{array}{l}\text { Td } \\
(\mathbf{s})\end{array}$ & Tc (s) & Tr (s) & Ts (s) & $\begin{array}{l}\text { Mp } \\
(\%)\end{array}$ \\
\hline PID_E_GTG & 3,5 & 34,61 & 46,56 & 191,81 & 9,34 \\
FLC_GTG & 2,5 & 36,55 & 63,64 & 161,4 & 6,9 \\
$\Delta$ & 1 & 1,94 & 17,08 & 20,41 & 2,44 \\
\hline
\end{tabular}

At Table 4, all parameters show that fuzzy control system response is slower than PID control system response with following characteristics: dead time (td) of $2.5 \mathrm{~s}$, a rise time (tr) of $69.87 \mathrm{~s}$, a time constant (tc) of $39.89 \mathrm{~s}$ and a settling time (ts) of $95.36 \mathrm{~s}$. However, maximum overshoot (Mp) generated by fuzzy control system $(6,9 \%=1,90 \mathrm{MMscfd})$ is relatively smaller and the PID control response $\mathrm{Mp}(9,34 \%=2,57 \mathrm{MMscfd})$.

From this result, we can compare these control systems by using 2 considerations. First, if we want a faster response without concern of overshoot value, then the PID is better. Of course, this option is not without consequences. A fast and sensitive response always need more energy. For this gas turbine generator system, it related to fuel that used. Second, if we want a slower and smoother response, then the fuzzy control system is better. This option will produce energy efficiency so that will also make an impact on production cost.

\section{CONCLUSION}

PID_E_GTG controller has faster response to time constant (Tc) and rise time (Tr). FLC_GTG can reach setting time (Ts) faster and has a smaller dead time (Td). can be specified controller type according to field requirements are more efficient and effective and fast when there is a change in load on the GTG

\section{ACKNOWLEDGMENTS}

The author extend the gratitude to Prof. Dr. Perry Burhan, M.Sc as a Director of Polytechnic Energy and Mineral Of Akamigas. Professional support and assistance from my teams and all respected reviewers have made this paper qualified to be published.

\section{REFERENCES}

[1] A. N. Isizoh, S. O. Okide, and A. A. E. O. C. D, "Temperature Control System Using Fuzzy Logic Technique," vol. 1, no. 3, pp. 27-31, 2012.

[2] H. S. AS Wardhana, M Ashari, "Optimal Control of Robotic Arm System to Improve Flux Distribution on Dual Parabola Dish Concentrator," Int. J. Intell. Eng. Syst., vol. 13, no. 1, pp. 364-378, 2020, doi: 10.22266/ijies2020.0229.34.

[3] A. S. Karande, "Design of a Fuzzy PID Controller for a Gas Turbine Power Plant," 2015.

[4] S. S. Patole and S. K. Mittal, "Fuzzy PID Controller Design for Heating," pp. 4989-4995, 2017, doi: 10.15662/IJAREEIE.2017.0606140.

[5] A. K. Dewi, A. E. Permanasari, and I. Hidayah, "Kesesuaian Minat Mahasiswa dengan Judul Tesis Mahasiswa Menggunakan Metode Fuzzy Mamdani," J. Rekayasa dan Teknol. Elektro, vol. 10, no. 1, pp. 1-10, 2016.

[6] M. Elnour and W. I. M. Taha, "PID and fuzzy logic in temperature control system," Proc. - 2013 Int. Conf. Comput. Electr. Electron. Eng. 'Research Makes a Differ. ICCEEE 2013, pp. 172-177, 2013, doi: 10.1109/ICCEEE.2013.6633927.

[7] M. Negnevitsky, Artificial Intelligence, 2nd ed. Pearson Education, 2005.

[8] B. Zohuri and N. P. Plants, "Gas Turbine Working Principles,” pp. 147-171, 2015, doi: 10.1007/978-3319-15560-9.

[9] M. P. Boyce, Gas Turbine Engineering Handbook, 4th ed. Wyman Street Walthman, USA, 2007. 